\title{
A defesa na Imprensa Militar do século XIX: Brasil e Argentina ${ }^{1}$
}

\section{Defense on the Milytary Press of the 19th Century: Brazil and Argentina}

Rev. Bra. Est. Def. v. 2, nº 2, jul./dez. 2015, p. 75-86

JOSÉ MIGUEL ARIAS NETO

\section{INTRODUÇÃO}

Esta exposição versará sobre uma parte do projeto "A imprensa militar: um estudo dos periódicos navais 1851-1882". Tentar-se-á compreender a formulação de uma ideia de defesa nacional em periódicos do Brasil e da Argentina no século XIX. Este texto é apenas uma aproximação inicial da questão. Advirto ao leitor que manterei no texto o tom mais informativo da exposição realizada na mesa $A$ dimensão epistêmica da defesa, ocorrida durante o $1^{\circ}$ Encontro Regional da Associação Brasileira de Estudos de Defesa / Sudeste, na sede do Programa de Pós-Graduação em Relações Internacionais San Tiago Dantas, na UNESP/SP.

\section{A DEFESA NO SÉCULO XIX}

A pergunta inicial é: há alguma discussão sobre defesa no século XIX?

Bem, pelas fontes disponíveis diria que não. E, no entanto, por acaso, muito por acaso, acabei me deparando com um conjunto de fontes onde essa discussão vai aparecer. Trata-se da imprensa militar que emerge como fenômeno internacional em meados do século XIX. Até este período, predominam as perspectivas e formulações aristocráticas sobre a guerra, decorrentes da persistência do Antigo Regime, que caracterizam as permanências de uma visão aristocrática de mundo até pelo menos metade do século XX. Evidentemente foi a Prússia, a partir de 1808, que criou o primeiro regulamento que obrigava a formação de militares em academias militares. Ainda assim pode-se afirmar que a discussão sobre defesa não 
acontece nas academias militares. Pelo menos no Brasil no século XIX, se forem verificados os programas de cursos de formação de oficiais da marinha, nada referente à defesa aparece. Também não aparece na documentação do governo. Quem faz uma reflexão sobre guerra, a partir da experiência da guerra, são militares: Clausewitz, Mahan, Jomini. E, no caso do Brasil, e em outros lugares, essa discussão vai aparecer aqui, na imprensa militar. E que imprensa é essa?

Ela já é uma imprensa que nasce internacional e decorrente da rápida modernização tecnológica que ocorre após a Segunda Guerra Mundial. As mudanças são dramáticas. Em 1850 a artilharia era composta de canhões com alma lisa, granadas sólidas e carregamento pela boca. Vinte anos mais tarde, em 1870, já existe artilharia raiada, balas explosivas e tubos lança-torpedos. Em termos de construção naval, na década de 1850 começa a surgir o revestimento da couraça de ferro, no caso dos navios e, em 1880, o casco já é inteiramente de aço. No ano de 1863, o comandante Francisco Manuel Barroso, chefe da divisão naval do Rio da Prata, em seu relatório para as autoridades navais destacava a situação do armamento dos navios lá estacionados:

O da corveta Berenice compõe-se de 14 canhões obuses de calibre 30, à Paixhans, cujo carretame e vestimenta se acha em bom estado. O de cada uma das canhoneiras de duas peças longas de calibre $68 \mathrm{em}$ rodízio, e de quatro peças da mesma qualidade, de calibre 32 em bateria, artilharia inglesa. Este armamento há quatro anos era o melhor que se conhecia, e o preferido por todas as potências marítimas; mas os canhões raiados depois disto vieram fazer uma completa revolução; de sorte que aquelas já não satisfazem as exigências da época. Forçosamente havemos de acompanhar este movimento progressivo da artilharia, embora com o sacrifício do atual material, e com novas despesas, se não quisermos ficar neste ponto em uma inferioridade deplorável” (Barroso, 1863, p. 2).

Os termos do relatório de Barroso são instigantes: revolução; progresso. Mas também é importante pensar o sujeito/inimigo oculto ou não enunciado, talvez porque de todos conhecido e que indicam a partir de que tipo de paradigma eram pensadas as forças navais neste período.

De fato, nos anos de 1863, várias guerras eram por demais conhecidas em seus resultados e efeitos: Crimeia (1853-1856), Segunda Guerra do Ópio (1856-1860), como estava em curso a Guerra Civil nos Estados Unidos (1860-1865). A famosa batalha de Hamtpon Roads (1862), na qual foram empregados dois navios encouraçados, o CSS Virginia (pela Confederação) e o USS Monitor (pela União). 
A modernização das Marinhas esteve, portanto, vinculada à Revolução Industrial, e é interessante verificar que nos anos de 1860, no vocabulário militar brasileiro, o termo revolução está vinculado à ideia de progresso técnico e suas consequências, como a possibilidade de multiplicação da potência de destruição de uma força armada, isto é, dos meios ou instrumentos da violência. É, pois, a esta revolução a que se refere Barroso - às drásticas transformações que ocorriam nos meios de produção da guerra. Estas consistiam em mudanças paradigmáticas, na medida em que um navio de madeira e a artilharia tradicional não eram antecessores naturais dos navios de ferro ou da artilharia raiada, que exigiam uma nova base produtiva.

Além disto, Barroso afirmava que o Brasil não poderia ficar em posição de inferioridade no quesito da artilharia. Para onde se dirigia o olhar de Barroso quando fez esta afirmação? Embora no próprio documento o chefe da divisão naval se remeta às "potências marítimas", seguramente não é a elas que ele pensa em se equiparar, quer no quesito artilharia, quer no quesito força naval. De fato, no momento em que redigia o seu relatório a esquadra brasileira era composta por aproximadamente 41 navios, sendo 15 a vela, 15 vapores de rodas, 13 vapores mistos (hélice/vela). Para efeitos comparativos, o Brasil possuía, em 1851, 59 navios, sendo 49 a vela e 10 a hélice. No mesmo período, em 1854, a Inglaterra possuía 491 navios de guerra, sendo 301 navios a vela, 77 a hélice e 113 vapores de rodas, enquanto que, em 1853, os EUA possuíam 74 navios de guerra, a Áustria 104, a Dinamarca 120, a Espanha 90, os Países Baixos 88, e Portugal 46. Assim, nos anos 1850 a esquadra brasileira poderia equiparar-se apenas à Portugal. ${ }^{2}$ Neste sentido, se Barroso olhava para a Europa e, especialmente para os EUA, cuja Marinha cresceu fantasticamente devido à Guerra Civil, no que diz respeito aos progressos técnicos que precisávamos adquirir, não era, certamente, nem nos EUA, nem na Europa que estava pensando quando afirmava a necessidade de equiparação de forças. Era a América do Sul, especialmente a recém-formada Argentina e o Paraguai, que nesta ocasião ampliava suas forças armadas, que estava no horizonte de Barroso.

Então as mudanças se processavam rapidamente e eram discutidas em uma imprensa que já nasce internacional. Não se trata, portanto, apenas do surgimento de periódicos em vários lugares do mundo, mas são periódicos que conversam entre si. Eles circulam, os artigos são traduzidos de um para outro e os próprios periódicos são enviados de um lugar para o outro.

Em um levantamento bastante incompleto feito a partir do catálogo da Biblioteca Imperial da França, de 1857, do Boletim do Centro Naval da Argentina do ano de 1882, e do Jornal da Biblioteca Britânica, pudemos verificar a existência de 20 periódicos ou mais relativos à discussão de temas 
navais. No caso do Brasil, a Revista Marítima Brasileira (RMB) não é apenas o periódico mais longevo, mas é o que tem o maior número de edições.

A partir de 1850 ocorrem duas coisas importantes: primeiro, o encerramento do tráfico negreiro e o deslocamento da agenda de relações internacionais do Brasil para a região do Prata. Mas, ao mesmo tempo, do ponto de vista da tecnologia, se há, desde a vinda da família real, um mercado editorial bastante consistente no Rio de Janeiro, no final da década de 1840, a implantação da prensa litográfica rotativa promoveu uma explosão das revistas ilustradas e uma grande dinamização da imprensa militar. Esta é uma imprensa que também já nasce em rede, porque já nasce traduzindo artigos de jornais estrangeiros e nasce discutindo com a grande imprensa do Rio de Janeiro. Fazendo uma contagem dos textos publicados pela RMB foi possível verificar o seguinte: dos quarenta artigos publicados sobre tecnologia no primeiro ano da revista, 30\%, ou seja, doze, são traduções. Então, eles já iniciam a publicação da revista inseridos neste debate internacional e dentro da perspectiva do iluminismo instrumental, que no caso do Império Português era chamado de reformismo ilustrado, que se desenvolveu a partir da administração pombalina, isto é, o programa iluminista do desenvolvimento científico e tecnológico. Este programa havia expurgado, portanto, aquilo que no período era conhecido como "abomináveis ideias francesas” (as ideias de liberdade e igualdade) e enfatizava o desenvolvimento científico e sua aplicabilidade tecnológica de modo a dinamizar o império português e o desenvolvimento econômico das colônias. É nesta perspectiva que nossa elite, formada prioritariamente em Coimbra, configurou o Estado brasileiro.

Neste sentido é importante perceber que a RMB discute a necessidade de nacionalização da marinharia, já que se contratavam muitos mercenários no exterior. Mas a revista defende também a indústria de construção naval nacional, mais precisamente o Arsenal de Marinha, contra a perspectiva de se adquirir navios construídos em estaleiros privados.

A revista também vai traçar planos para a organização da Marinha e das esquadras. A carreira, o montepio militar, o asilo de inválidos, as promoções e os soldos serão objetos de preocupação da revista ao lado de temas como o recrutamento, a profissionalização, a reforma do Regimento Provisional, que era o regimento que regia a disciplina naval. A RMB também procura se fazer porta-voz dos interesses da "classe militar" na medida em que procura participar da discussão parlamentar acerca da fixação das forças navais anuais e propugna a criação de um conselho naval.

Os editores da revista tem formação na Academia da Marinha. Giacomo Raja Gabaglia, que faleceu em 1870, era membro do Instituto Histórico Geográfico Brasileiro, e fez parte daquela grande expedição científica que 
a IHGB faz para o Ceará nos anos 1850. Ele também estudou construção hidráulica na Europa. O Sabino Eloi Pessoa, também, foi bibliotecário, lente da Academia da Marinha, secretário do Conselho Naval. Em 1868 ele pede demissão do serviço da armada, mas em 1881 ele volta como editor de outra revista de Marinha.

Para os editores da RMB havia uma clara definição do que era a Defesa Nacional no século XIX e qual o lugar da Marinha neste conjunto.

A marinha é por essência a base da força e da influência política dos estados, a protectora nata do commercio, o elemento primordial da prosperidade material das nações, e por tal forma tem contribuído para o desenvolvimento da civilização que chegou a constituir-se no mundo uma força superior cuja direção suprema envolve o futuro das sociedades humanas. [E enunciando um paradigma que fez escola no pensamento militar ao longo do século XIX e XX ainda acrescenta:] $\mathrm{E}$ com a força que ha podemos defender a nossa liberdade e a honra nacional? Poderá essa força ser porventura um antemural de nossa independência, uma garantia de ordem e prosperidade para o vasto império destinado pela providência a ocupar lugar distinto no catálogo das principaes nações marítimas do mundo? (Revista Marítima Brasileira, 1854, p. 5, grifos do autor).

Aparentemente muito simples, caberia à Marinha a defesa do comércio e da prosperidade da nação. Mas o artigo vai muito além, pois a Marinha deveria ser a força e a projeção de potência dos estados, uma força superior na construção da civilização do presente e do futuro. No conjunto da defesa nacional caberia à Marinha a defesa da independência, isto é, a manutenção da integridade territorial e garantia da ordem, isto é, de uma determinada ordenação da propriedade e de uma projeção de potência imperial no Rio da Prata e na América do Sul.

No já citado relatório da divisão naval do Rio da Prata de 1863, Barroso afirmava:

Não podendo, nem devendo nós manter uma marinha grande, parece, contudo de intuição, que os poucos navios que tivermos, devem preencher todas as condições de perfectibilidade introduzidas nas marinhas militares mais adiantadas [...]. A defesa do País está exigindo a cada momento, que a nossa marinha de guerra sofra também a transformação que se vai operando aos nossos olhos, na França, na Inglaterra, e nos Estados Unidos; sob pena de ficar inutilizada no momento preciso; de não poder desempenhar a sua missão; de não corresponder ao apelo da Pátria nos seus dias de aflição, com vergonha para o governo, e desar para a Corporação. Para salvar interesses tão caros; para poupar-nos à futuras humi- 
lhações, não há quantia alguma, por mais avultada que pareça que tenha importância. A economia neste ponto alia-se pouco com a dignidade nacional, e para selar esta, é preciso sacrificar um pouco aquela, e creio que nenhum brasileiro quererá que se faça o contrário (Barroso, 1863, p. 2).

É importante destacar que, como já se havia notado aqui, a Europa e os EUA são as referências de Barroso para a constituição da Força Naval do ponto de vista tecnológico. Há, no entanto, nesta passagem outras associações que são importantes para destacar o conceito de defesa em construção no Oitocentos. Em primeiro lugar, se não for possível desempenhar a missão da defesa, se não puder corresponder ao chamado da pátria, isto será uma vergonha para o governo e um desar para a corporação. Esta associação entre pátria-governo-corporação compõe o sujeito e o objeto da defesa: a Pátria (o objeto), o governo e os militares (os sujeitos). Caberia aos segundos, especialmente aos governos, o financiamento das forças armadas, cujos cálculos não seguiriam, aparentemente, um raciocínio lógico que tomaria em consideração o fator econômico, visto que nenhuma quantia, "por mais avultada que seja", tem importância diante da sacralidade da missão confiada aos militares, a defesa da Pátria. Este argumento é corrente entre os militares no século XIX, encontrando-se o mesmo em inúmeros documentos e mesmo na imprensa militar. É só aparentemente que se constitui um exagero. De fato, é uma resposta a uma fala também corrente entre os políticos civis, de que a guerra é um desar, um mal necessário e que despesas militares são improdutivas. É na medida do crescimento da oposição entre civis e militares que já se enuncia na imprensa dos anos 1850 em diante, que este se tornará um diálogo de surdos até que configure uma contradição insuperável. Assim, não é de somenos o argumento de Barroso e nem constitui um absurdo redigido por um militar tão circunspecto quanto o chefe da divisão do Rio da Prata. De fato, neste mesmo relatório ficam explícitos os limites do que seria a defesa no século XIX. Traçando suas considerações finais acerca da missão da divisão, Barroso observava:

Os navios de guerra da Divisão, em hombridade neste porto com os das primeiras nações marítimas, não se mostram inferiores à eles nem em asseio, nem em disciplina, e vão desempenhando, como devem a sua missão essencial de proteger os interesses nacionais, e a marinha mercante do Império, que frequenta em grande escala o Rio da Prata. Não se deve, pois, calcular somente a utilidade da Divisão pelas comissões que ela executou; mas principalmente pela força moral que dela irradia para garantia de tão importantes interesses (Barroso, 1863, p. 9). 
Embora não empregue o termo “dissuasório”, é exatamente este o papel que atribui à sua Divisão, pois ela é importante não só "pelas comissões que ela realizou, mas pela força moral que dela irradia para a garantia de tão importantes interesses". Em outras palavras, a política de defesa no século XIX seria a implantação de forças militares que representassem uma presença moral, uma força da qual irradiasse a garantia dos interesses comerciais do Brasil, da qual irradiasse uma projeção de potência na América do Sul, a garantia da propriedade e do desenvolvimento do capitalismo nascente nestas plagas e a liderança do Império do Brasil na região. Esta seria a projeção de custos e o limite para o financiamento das forças militares no Brasil. Verifica-se, portanto, que a ideia de defesa cunhada nos anos 1850 pelos redatores da RMB projetou-se no tempo e coadunava-se com as expectativas da corporação.

$\mathrm{Na}$ Argentina verifiquei a existência de seis revistas que caracterizariam uma impressa militar. São elas: Revista Militar (1875), Revista Militar y Naval (1881-1883), Boletim del Centro Naval (1884-nd.); Revista Militar Argentina (1887), Revista de La Union Militar (1890) e Almanaque Prensa Militar (1898). A Revista Militar e Militar y Naval eram institucionais publicadas pelo Ministério da Guerra e Marinha, os outros boletins estão vinculados a associações militares, o Boletim do Centro Naval ao Centro Naval, a Revista Militar Argentina ao Clube Militar e a Revista da União Militar à União Militar. Essas revistas são predominantemente históricas, ou seja, elas fazem a história da instituição ao mesmo tempo que articulam também uma discussão sobre a organização das forças militares argentinas em seus aspectos técnicos e humanos.

Também nelas há um discurso acerca do dever da defesa. De acordo com a Revista Militar:

Es, pues, un deber del pais, mantener su defensa nacional en el estado que le indica la posicion de su território, el numero de sus ciudadanos y los interesses que tiene que proteger. Asi es que la mayor parte de las naciones civilizadas, y aun las mas pacificas, han organizado sus milicias de un modo tal que las permita utilizar en cualquier emergencia todos los recursos del pais en hombres instruyendoles de antemano en servicio de las armas (Revista Militar, 1875, p. 3).

Para a Revista Militar a defesa nacional implica na preservação do território, dos cidadãos, do estado e da ordem de propriedade, isto é, dos interesses capitalistas que têm que proteger. Assim, é preciso mobilizar os recursos necessários que possam ser mobilizados em qualquer emergência.

O Boletim do Centro Naval avança nesta definição, delineando mais especificamente os lugares a serem ocupados pela Marinha e seus homens na defesa nacional: 
La Marina Argentina, tiene vastos horizontes ante sí, puede perfectamente llenar su mision en bien, no solamente de esta nuestra patria, sino tambien en pró de la humanidad toda; ella es uno de los elementos más poderosos que deben contribuir al desarrollo de nuestras grandes riquezas. No es permaneciendo en la oscuridad que los Oficiales subalternos de la Armada pueden propender a la más pronta realización de las reformas que es necesario introducir en la Armada para su mejor y definitiva reorganizacion; todos deben contribuir a tan patriótico fin, y deber es de los subalternos ayudar a sus Superiores en la esfera de sus fuerzas. [...] queremos que el Gobierno y el país sepan que tienen Oficiales de marina dignos de llevar tan distinguido como honroso uniforme y que, prosiguiendo en el trabajo y en el deber, dén glorias a la patria en la paz y en la guerra! (Boletin del Centro Naval, 1884, p. 5-7).

Destaca-se que os editores do Boletim - assim como os da RMB em 1850 - atribuem às Marinhas um papel de alcance universal, abarcando toda a humanidade, que é o de contribuir para o desenvolvimento das riquezas nacionais. Para isto, o oficial não deveria permanecer na obscuridade, mas ocupar o centro da ação política, para realizar as reformas e a reorganização que a Marinha necessita para atuar na guerra e na paz na consecução da manutenção da ordem e do desenvolvimento econômico.

\section{CONSIDERAÇÕES FINAIS}

Verifica-se, pois, com base em uma preliminar observação da imprensa militar e de demais documentação do século XIX, que a ideia de defesa está vinculada num sentido amplo e genérico ao desenvolvimento econômico e à expansão da sociedade capitalista. Mais especificamente, a ideia de defesa se prende à consolidação e manutenção de uma determinada ordem de propriedade, o que, em termos de desenvolvimento do Estado Moderno, significa a defesa das fronteiras, da unidade nacional e das rotas de comércio, do progresso econômico.

Derivado destas preocupações mais amplas, ao menos no caso de Brasil e da Argentina, predomina a noção de dissuasão, ou seja, não há uma projeção expansionista militar, a despeito de haver, em alguns momentos conflitos em torno de definições territoriais. Brasil e Argentina não desenvolveram e não tinham a pretensão de desenvolver forças militares vinculadas a um processo de conquista, como foi o caso dos Estados Unidos, por exemplo.

Um terceiro elemento é importante. Neste conceito de defesa a história da guerra vai ocupar um espaço importante e isto se manifesta nos pe- 
riódicos navais elencados, pois a história da guerra tem a função de criar a identidade das corporações e dos militares, ela tem uma função cívica e pedagógica de reproduzir uma memória institucional heroica. Por isto, desde o início a História Militar feita pelas instituições militares é fundamentada na perspectiva da magistra vitae e no âmbito da história exemplar, não comportando a dimensão de análise crítica da guerra, das instituições e das corporações.

A organização das forças militares, a carreira implicando a discussão de uma formação especializada estão imbricadas na ideia da defesa na medida em que dois aspectos preocupam estes intelectuais do Oitocentos: como articular a estrutura social, econômica e cultural e a profissionalização de um oficial militar, em suma: como seria o recrutamento e a formação deste oficial? Não é ao acaso que os editores da RMB são abolicionistas. Eles partilhavam das ideias de José Bonifácio, que afirmava ser uma sociedade escravista obstáculo à constituição de Forças Armadas homogêneas e harmônicas

A ciência e a tecnologia aplicadas à defesa é um outro elemento fundamental para o tema da defesa no século XIX. Havia, desde o início do século XIX, a clara consciência de que sem o desenvolvimento industrial a tendência ao aprofundamento da dependência em relação aos centros industrializados seria crescente. Não é ao acaso que no Brasil o primeiro núcleo industrial é militar: os arsenais da Marinha e da Guerra, fábricas de municiamento e de pólvora, de modo que o pensamento industrializante aprofundou-se na mentalidade militar do século XX.

$\mathrm{E}$, finalmente, os sentidos que o termo "defesa" adquire no século XIX, é um sentido que é internacionalizado e se dá a partir dessa rede de discussão entre militares e que avançou ao século XX, pelo menos até 1945 , quando o domínio da energia nuclear reconfigura totalmente o paradigma da defesa e da guerra.

Obrigado!

\section{REFERÊNCIAS}

\section{Fontes:}

BRASIL. Relatórios da Secretaria de Estado dos Negócios de Marinha (1850-1900).

BRASIL. Relatório da divisão naval do Rio da Prata (1863) - IHGB.

Revista Marítima Brasileira (1851-1855; 1881-18??).

Revista Militar (1875). 
RBED, v. 2, nํ 2, jul./dez. 2015

Revista Militar y Naval (1881-1883).

Boletim del Centro Naval (1884-18??).

Revista Militar Argentina (1887).

Revista de La Union Militar (1890).

Almanaque de La Prensa Militar (1898).

\section{Bibliografia}

ARIAS NETO, J. M. A Revista Marítima Brasileira - 1851-1855: Um projeto de Marinha para o Império do Brasil. In: PAULA, L. C. C. de; RESTIER JUNIOR, R. J. P.; LOUREIRO, M. J. G.; CHAGAS, F. M. da S. (Org.). A guerra e a formação dos Estados Nacionais contemporâneos. 1. ed. Rio de Janeiro: Multifoco, 2013, p. 116-139.

Em busca da cidadania: praças da Armada Nacional 1867-1910. Tese (Doutorado). São Paulo: USP, 2001.

. Revista Marítima Brasileira: 1851-1855 - A Liberdade de Pensamento na Marinha Imperial e o Projeto de Nação no século XIX. Revista Brasileira de História Militar, v. 8, p. 4-29, 2012.

BARROSO, F. M. Ofício n ${ }^{\circ} 24-$ Apresentando relatório do Comando da Divisão Naval do Rio da Prata, relativo ao ano de 1862. Divisão Naval do Rio da Prata, 1863. 37 p.

BENTIVOGLIO, J. Historiografia e máquinas de guerra: a história da história como um estudo de relações de forças com breves apontamentos sobre a Escola Histórica Alemã e a Escola dos Annales. História Revista, Goiânia, v. 17, n. 1, p. 223-238, jan./jun. 2012.

COSTA, D. Conselheiro Sabino Eloi Pessoa (1821-1897). Revista Marítima Brasileira, Rio de Janeiro, n. 9-10, p. 939-973, 1939.

COSTA, V. P. A espada de dâmocles: o exército, a guerra do Paraguai e a crise do Império. São Paulo: HUCITEC/Editora da UNICAMP, 1996.

DARNTON, R. Os dentes falsos de George Washington: um guia não convencional para o século XVIII. São Paulo: Companhia das Letras, 2005.

DELEUZE, G.; GUATTARI, F. Mil Platôs: capitalismo e esquizofrenia. Tratado de nomadologia. Vol. 5. São Paulo: Ed. 34, 1997.

DUBY, G. O domingo de Bouvines: 27 de julho de 1214. Rio de Janeiro: Paz e Terra, 1993. 
GUIMARÃES, M. L. S. Historiografia e nação no Brasil 1838-1857. Rio de Janeiro: EdUERJ, 2011.

KRACAUER, S. O ornamento da massa. São Paulo: Cosacnaif, 2009.

KURY, L. (Org.). Iluminismo e Império no Brasil: O patriota ( 1813-1814). Rio de Janeiro: Editora Fiocruz, 2007.

MOREL, M. As transformações dos espaços públicos: imprensa, atores políticos e sociabilidades na cidade imperial ( 1820-1840). 2. ed. Rio de Janeiro: Hucitec, 2010.

RÉMOND, R. (Dir.). Pour une histoire politique. Paris: Seuil, 1988.

TARDE, G. A opinião e as massas. São Paulo: Martins Fontes, 2005.

WILLIAMS, R. Cultura e materialismo. São Paulo: Editora UNESP, 2011.

\section{NOTAS}

1. Esta exposição é parte do projeto "A imprensa Militar: um estudo dos periódicos navais 1851-1882".

2. Fontes: Relatório da Secretaria de Negócios da Marinha, 1864 e Revista Marítima Brasileira, 1854. 


\section{A DEFESA NA IMPRENSA MILITAR DO SÉCULO XIX: BRASIL E ARGENTINA"}

\section{RESUMO}

Este texto faz uma primeira prospecção acerca da concepção de Defesa Nacional presente no pensamento militar brasileiro e argentino, expresso através de documentação variada e de publicações editadas por oficiais de marinha.

Palavras chave: Imprensa Militar; Defesa; Oitocentos.

\section{ABSTRACT}

This paper is a first survey on the design of National Defense present in the Brazilian and Argentine military thinking expressed by varied documentation and edited publications by naval officers.

Key-words: Military Press; Defense; Eight Hundred. 